\title{
Coronary event and case fatality rates in an English population: results of the Oxford myocardial infarction incidence study
}

J A Volmink, J N Newton, N R Hicks, P Sleight, G H Fowler, H A W Neil, on behalf of the Oxford Myocardial Infarction Incidence Study Group
Mortality from coronary heart disease (CHD) has been decreasing over the past two decades in the UK and most Western industrialised countries. In England and Wales between 1972 and 1989 age adjusted mortality fell by $33 \%$ in men and $23 \%$ in women aged $30-69$ years ${ }^{1}$ but there are wide geographical variations. ${ }^{23}$ The relative contribution of coronary event and case fatality rates to temporal and geographical variation in mortality from CHD remains poorly understood, and there is concern that inpatient case fatality in England may not have declined since the early 1980s despite major advances in treatment. ${ }^{4}$

The aim of the Oxford myocardial infarction incidence study (OXMIS), a 12 month prospective, surveillance study, was to identify all patients with acute myocardial infarction among a population of 568800 in Oxfordshire, England, in 1994-95 using World Health Organisation monitoring trends and determinants of cardiovascular disease (MONICA) project diagnostic criteria. ${ }^{5}$ It provides the only data for an English population that are comparable with the MONICA data for Glasgow and Belfast. We report coronary event and case fatality rates and compare these with previously published data from a study conducted in the same county in $1966-67 .^{67}$

\section{Methods}

Patients less than 80 years of age with first or recurrent myocardial infarction who were resident in Oxfordshire were registered in the study, irrespective of whether the event occurred in the study area. Patients were excluded if onset of the event was outside the study period, or occurred within 28 days of a preceding event. The resident population of Oxfordshire was based on the mid-1994 population estimates for the health authority. The study was approved by the central Oxford research ethics committee.

\section{CASE ASCERTAINMENT}

Multiple overlapping sources of case ascertainment were used to register patients with suspected infarction. Most non-fatal events were identified prospectively within hours to days of onset of the attack using the method previously referred to as "hot pursuit". ${ }^{8}$ This involved searching the computerised hospital admission system daily and inquiring from staff in coronary care units and other medical wards, to identify patients with potential infarction admitted during the previous 24

Sciences, Old Road,

Headington, Oxford OX 3

7LF, UK. 
Table 1 Annual event rates per 100000 population for fatal and non-fatal first and recurrent coronary events in men and women

\begin{tabular}{|c|c|c|c|c|c|c|c|}
\hline \multirow{2}{*}{$\begin{array}{l}\text { Age group } \\
\text { (years) }\end{array}$} & \multirow[b]{2}{*}{ Population } & \multicolumn{2}{|c|}{ Non-fatal definite $M I$} & \multicolumn{2}{|c|}{ Non-fatal possible MI } & \multicolumn{2}{|c|}{ Fatal events } \\
\hline & & Number & Rate & Number & Rate & Number & Rate \\
\hline \multicolumn{8}{|l|}{ Men } \\
\hline$<35$ & 155283 & 5 & 3.2 & 0 & 0 & 0 & 0 \\
\hline $35-49$ & 62321 & 38 & 61.0 & 11 & 17.7 & 20 & 32.1 \\
\hline $50-64$ & 43378 & 136 & 313.5 & 44 & 101.4 & 90 & 207.5 \\
\hline $65-79$ & 27230 & 163 & 598.6 & 44 & 161.6 & 225 & 826.3 \\
\hline \multicolumn{8}{|l|}{ Women } \\
\hline$<35$ & 143283 & 0 & 0 & 0 & 0 & 0 & 0 \\
\hline $35-49$ & 60339 & 6 & 9.9 & 3 & 5.0 & 2 & 3.3 \\
\hline $50-64$ & 43599 & 38 & 87.2 & 14 & 32.1 & 23 & 52.8 \\
\hline $65-79$ & 33218 & 90 & 270.9 & 40 & 120.4 & 159 & 478.7 \\
\hline
\end{tabular}

Fatal events include definite myocardial infarction (MI), possible MI, and unclassifiable death.

hours. The results of serum cardiac enzyme estimations were examined daily, and results of electrocardiography (ECG) carried out in hospital were obtained monthly. General practitioners were also asked to notify, by telephone, patients with suspected myocardial infarction or coronary death.

Retrospective scrutiny of routine sources of information, "cold pursuit", was used to identify patients with fatal infarctions and some with non-fatal events. The contract minimum datasets compiled by Oxfordshire Health Authority were searched to detect patients discharged with a diagnosis of myocardial infarction. This method was important for identifying patients treated outside Oxfordshire. Death certificates for Oxfordshire residents were examined and those with International Classification of Diseases, ninth revision, codes 410 to 414 were registered. Necropsy reports were scrutinised to identify deaths caused by CHD. Cause specific mortality statistics compiled by the Office for Population Censuses and Surveys were also examined.

Where possible, patients were interviewed to obtain details of the acute event and any previous coronary events; where death occurred, the closest relative was interviewed. Information obtained by interview was supplemented by review of case notes together with ambulance, police, and coroners reports. The previous study conducted in $1966-67^{7}$ used similar methods and both studies used the same procedures for case ascertainment.

Table 2 Annual event rate per 100000 population for first and recurrent events in men and women aged 35 to 79 years using different coronary event definitions after age standardisation to a world standard population

\begin{tabular}{|c|c|c|c|c|c|c|}
\hline \multirow[b]{3}{*}{ Age group (years) } & \multicolumn{6}{|c|}{ Coronary event definitions } \\
\hline & \multicolumn{2}{|l|}{1} & \multicolumn{2}{|l|}{2} & \multicolumn{2}{|l|}{3} \\
\hline & Rate & $95 \% C I$ & Rate & $95 \% C I$ & Rate & $95 \% C I$ \\
\hline \multicolumn{7}{|l|}{ Men } \\
\hline $35-64$ & 273 & 241,304 & 271 & 239,302 & 325 & 290,359 \\
\hline $65-79$ & 1350 & 1210,1490 & 1290 & 1160,1420 & 1500 & 1350,1640 \\
\hline \multicolumn{7}{|l|}{ Women } \\
\hline $35-64$ & 66 & 50,82 & 61 & 46,76 & 82 & 65,100 \\
\hline $65-79$ & 677 & 589,765 & 661 & 574,748 & 784 & 689,879 \\
\hline
\end{tabular}

Event definition 1 includes non-fatal and fatal definite myocardial infarction (MI), fatal possible $\mathrm{MI}$, and unclassifiable coronary death.

Event definition 2 includes non-fatal and fatal definite MI, and fatal possible MI.

Event definition 3 includes non-fatal and fatal definite MI, non-fatal and fatal possible MI, and unclassifiable coronary death
DIAGNOSTIC CRITERIA

The diagnosis of myocardial infarction was validated using WHO MONICA criteria, which are primarily based on symptoms, ECG findings, cardiac enzymes, and necropsy reports. ${ }^{9}$ ECGs were coded by trained coders at the Glasgow MONICA centre using a combination of MONICA protocol criteria and the Minnesota code manual of electrocardiographic findings. ${ }^{10}$ Each event was assigned to one of five diagnostic categories: definite myocardial infarction, possible myocardial infarction, ischaemic cardiac arrest, fatal infarction with insufficient data (also termed unclassifiable death), and no acute myocardial infarction.

\section{EVENT DEFINITIONS}

Three coronary event definitions employed in the MONICA project were used ${ }^{11}$ : event definition 1 includes all coronary events that satisfy the criteria for non-fatal definite myocardial infarction or coronary death (fatal definite infarction, fatal possible infarction, or unclassifiable death); event definition 2 is the same as definition 1, except for exclusion of unclassifiable deaths; and event definition 3 retains unclassifiable deaths (as in definition 1) and adds non-fatal possible infarction.

Event definition 1 was used for reporting coronary event and case fatality rates, unless specifically indicated otherwise, because it allows the most reliable geographical and temporal comparisons of rates.

The coronary event rate was defined as the rate of first or recurrent coronary events (whether fatal or non-fatal) per 100000 population per year. The first event rate was defined as the rate in that part of the population not known to have previously suffered a myocardial infarction. An event that occurred more than 28 days after any previous event in the same person was considered to be a new event.

Events were classified as fatal or non-fatal depending on whether the patient survived the first 28 days from onset of symptoms. The overall case fatality rate at 28 days was the proportion of patients who died within 28 days of onset of symptoms, and the out of hospital case fatality rate was the proportion of these patients who died before reaching hospital. Sudden death rates, rather than out of hospital case fatality rates, were used in the Oxford study $^{67}$ in 1966-67 and were calculated for 1994-95 to allow comparison. Sudden death was defined as a fatal infarction in which death occurred before the patient could be seen by a doctor. The 28 day case fatality rate for hospitalised patients was defined as the proportion of patients who received hospital treatment and died by day 28 .

\section{STATISTICAL ANALYSIS}

Event rates for men and women were age adjusted by direct standardisation by five year age group using Segi's standard world population. ${ }^{12}$ Case fatality rates were age standardised using weights derived from either the age distribution of coronary events in the MONICA project, ${ }^{10}$ or the age distribution of patients in the OXMIS. Normal approximation 
Table 3 Age specific and age standardised event rates ${ }^{\star}$ per 100000 population for first and recurrent coronary events in men and women aged 30 to 69 years in 1994-95 compared with 1966-67

\begin{tabular}{|c|c|c|c|c|}
\hline & \multicolumn{2}{|l|}{ Rate } & \multicolumn{2}{|c|}{ Change in rates } \\
\hline & 1966-67 & 1994-95 & $\%$ & $95 \% C I$ \\
\hline \multicolumn{5}{|l|}{ Men } \\
\hline \multicolumn{5}{|l|}{ Non-fatal definite MI } \\
\hline $30-49$ years & 70.4 & 46.8 & -33.5 & $-72.3,54.1$ \\
\hline $50-69$ years & 365.5 & 358.2 & -2.0 & $-23.9,19.8$ \\
\hline Age standardised & 188.4 & 171.4 & -9.0 & $-27.8,9.8$ \\
\hline \multicolumn{5}{|l|}{ All fatal events } \\
\hline $30-49$ years & 77.7 & 22.8 & -70.7 & $-105.8,-37.3$ \\
\hline $50-69$ years & 494.7 & 266.8 & -46.1 & $-63.3,-29.3$ \\
\hline Age standardised & 244.5 & 120.4 & -50.8 & $-64.9,-36.6$ \\
\hline \multicolumn{5}{|l|}{ All events } \\
\hline $30-49$ years & 148.8 & 69.7 & -53.2 & $-78.6,-27.6$ \\
\hline $50-69$ years & 861.3 & 625.0 & -27.4 & $-40.9,-13.9$ \\
\hline Age standardised & 433.8 & 291.8 & -32.7 & $-44.1,-21.3$ \\
\hline \multicolumn{5}{|l|}{ Women } \\
\hline \multicolumn{5}{|l|}{ Non-fatal definite MI } \\
\hline $30-49$ years & 8.5 & 7.2 & -15.3 & $-130.6,103.5$ \\
\hline $50-69$ years & 71.5 & 114.8 & 60.6 & $6.5,114.4$ \\
\hline Age standardised & 33.7 & 50.2 & 50.0 & $0.0,99.7$ \\
\hline \multicolumn{5}{|l|}{ All fatal events } \\
\hline $30-49$ years & 5.5 & 2.4 & -56.4 & $-210.9,71.6$ \\
\hline $50-69$ years & 163.5 & 105.5 & -35.3 & $-64.8,-5.8$ \\
\hline Age standardised & 68.7 & 43.6 & -36.5 & $-64.2,-8.9$ \\
\hline \multicolumn{5}{|l|}{ All events } \\
\hline $30-49$ years & 13.9 & 9.5 & -31.7 & $-126.6,55.0$ \\
\hline $50-69$ years & 235.0 & 220.5 & -6.2 & $-32.4,20.1$ \\
\hline Age standardised & 102.3 & 93.9 & -8.2 & $-33.1,16.7$ \\
\hline
\end{tabular}

^ Rates for both studies are directly standardised to a world standard population

methods were used to calculate $95 \%$ confidence intervals (CI) for age standardised rates, changes in age standardised rates, and changes in age specific rates. ${ }^{13-15}$

\section{Results}

Between 14 November 1994 and 13 November 1995, a total of 1343 patients with suspected infarction were identified. These comprised 648 definite myocardial infarctions, 462 possible myocardial infarctions, five ischaemic

Table 4 Age specific and age standardised fatality rates * at one month for all cases, hospitalised cases, and for sudden death in men and women aged 30 to 69 years in 1994-95 compared to 1966-67

\begin{tabular}{|c|c|c|c|c|}
\hline & \multicolumn{2}{|c|}{ Fatality rate $\%$ (number of deaths) } & \multicolumn{2}{|c|}{ Change in fatality rates } \\
\hline & $1966-67$ & $1994-95$ & Percentage & $95 \% C I$ \\
\hline \multicolumn{5}{|l|}{ Men } \\
\hline \multicolumn{5}{|l|}{ All cases } \\
\hline $30-49$ years & $52.7(29)$ & $32.8(20)$ & -37.8 & $-71.3,-4.4$ \\
\hline $50-69$ years & $57.5(134)$ & $42.7(146)$ & -25.7 & $-40.2,-11.5$ \\
\hline Age standardised & 56.7 & 41.0 & -27.7 & $-40.9,-14.5$ \\
\hline \multicolumn{5}{|l|}{ Hospitalised cases } \\
\hline $30-49$ years & $37.2(12)$ & $2.4(1)$ & -93.5 & $-134.4,-53.0$ \\
\hline $50-69$ years & $25.2(22)$ & $18.0(43)$ & -28.7 & $-65.5,8.3$ \\
\hline Age standardised & 27.2 & 15.4 & -43.4 & $-72.8,-14.0$ \\
\hline \multicolumn{5}{|l|}{ Sudden death } \\
\hline $30-49$ years & $27.3(15)$ & $29.5(18)$ & 8.1 & $-52.0,68.5$ \\
\hline $50-69$ years & $41.6(97)$ & $26.3(90)$ & -36.8 & $-53.8,-17.9$ \\
\hline Age standardised & 39.2 & 26.8 & -31.6 & $-49.5,-13.8$ \\
\hline \multicolumn{5}{|l|}{ Women } \\
\hline \multicolumn{5}{|l|}{ All cases } \\
\hline $30-49$ years & $40.0(2)$ & $25.0(2)$ & -37.5 & $-93.5,1.7$ \\
\hline $50-69$ years & $69.6(48)$ & $48.0(59)$ & -31.0 & $-51.1,-10.9$ \\
\hline Age standardised & 64.6 & 44.1 & -31.7 & $-55.0,-8.5$ \\
\hline \multicolumn{5}{|l|}{ Hospitalised cases } \\
\hline $30-49$ years & $0(0)$ & $14.3(1)$ & - & - \\
\hline $50-69$ years & $54.5(18)$ & $22.9(19)$ & -58.0 & $-89.7,-26.4$ \\
\hline Age standardised & 45.5 & 21.5 & -52.7 & $-87.0,-18.5$ \\
\hline \multicolumn{5}{|l|}{ Sudden death } \\
\hline $30-49$ years & $40.0(2)$ & $12.5(1)$ & -68.8 & $-190.5,15.0$ \\
\hline $50-69$ years & $37.7(26)$ & $28.5(35)$ & -24.4 & $-124.9,61.5$ \\
\hline Age standardised & 38.1 & 25.8 & -32.3 & $-68.8,4.2$ \\
\hline
\end{tabular}

* 1966-67 rates are directly standardised to the age distribution of OXMIS cases.

The 30 day case fatality rate in 1966-67 was compared with the 28 day case fatality rate in 1994 95. The duration of the earlier study was nine months and the population studied was 375000 . Sudden deaths were defined as coronary deaths that occurred before the patient was seen by a doctor. cardiac arrests, 41 unclassifiable deaths, and 187 without evidence of a myocardial infarction.

\section{CORONARY EVENT RATES}

Table 1 shows the annual age specific rate for first and recurrent coronary events in men and women aged less than 80 years. Table 2 gives the annual event rates for MONICA event definitions 1,2, and 3 for men and women aged 35-64 and 65-79 years after age standardisation to a standard world population. ${ }^{12}$ At younger ages, a higher proportion of events were first events. In the age group 35-64 years, the age standardised first event rate per 100 000, using event definition 1 (non-fatal definite infarction and coronary death), was 189 (95\% CI 162 to 215 ) in men and 58 (44 to 73 ) in women. In the age group 65-79 years, the first event rate was 788 (95\% CI 682 to 894 ) in men and 493 (95\% CI 417 to 570 ) in women. These may underestimate first event rates as it was not possible to determine whether there was a history of a previous infarction in 19 patients aged $35-64$ and in 58 aged $65-79$ years.

COMPARISON OF CORONARY EVENT RATES FOR

1994-95 AND 1966-67

Table 3 shows rates of non-fatal definite infarctions, fatal events, and all events in men and women aged 30-69 years for 1994-95 and 1966-67 after age standardisation to a standard world population. ${ }^{12}$ Over this period the age standardised event rate in men fell significantly by one third, but in women there was a non-significant decline of $8 \%$. The reduction in event rate in men was much greater in the 30-49 year old group than in those aged 50-69 years. Similarly, there was a larger reduction in event rate in younger women, but the $95 \%$ CIs were wide. The rate of non-fatal infarctions in women seems to have increased largely because of an increase of $60 \%$ in the age specific rate in the $50-69$ year age group. Age standardised mortality declined by about half in men and by over a third in women.

\section{CASE FATALITY RATE}

During the study period, 519 coronary deaths occurred within 28 days of event onset. Of these deaths, $361(69.6 \%)$ occurred outside hospital and $296(82.0 \%)$ were medically unattended. The overall crude 28 day case fatality rate, which includes out of hospital deaths, was $52.2 \%$ for patients younger than 80 years of age. Case fatality increased sharply with age from $34.5 \%$ in men aged $35-49$ years to $58.0 \%$ in those aged $65-79$, and there was a corresponding increase in women from $25.0 \%$ to $63.9 \%$. Under the age of 80 years the crude 28 day case fatality for hospitalised patients was $24.9 \%$ and the out of hospital case fatality was $36 \%$.

After direct standardisation to the age distribution of MONICA cases, the overall 28 day case fatality for men aged less than 65 years was $38.6 \%$ (95\% CI 31.7 to 46.3 ), the out of hospital case fatality was $30.3 \%$ (95\% CI 23.9 to 
36.8 ), and the 28 day case fatality for hospitalised cases was $12.2 \%$ (95\% CI 7.4 to 17.0$)$. For women in this age group the corresponding rates were $36.1 \%(95 \%$ CI 21.4 to 50.7$)$, $25.7 \%$ (95\% CI 13.4 to 38.0 ), and $14.0 \%$ (95\% CI 3.3 to 24.6 ). For hospitalised patients surviving 24 hours, however, the 28 day rates were lower: $9.9 \%$ (95\% CI 5.4 to 14.3 ) in men and $4.9 \%(95 \% \mathrm{CI}-2.1$ to 11.9$)$ in women.

COMPARISON OF CASE FATALITY RATES FOR

1994-95 AND 1966-67

Table 4 shows the one month age specific and age standardised case fatality (after standardisation to age distribution in the OXMIS) for 1994-95 and 1966-67 in individuals aged 30-69 years. Overall case fatality declined significantly by $28 \%$ in men and $32 \%$ in women. The age standardised case fatality among hospitalised patients declined significantly by $43 \%$ in men and $53 \%$ in women. Age standardised case fatality for sudden death declined by $32 \%$ for both sexes. In women, however, the $95 \%$ CI for the decline overlapped zero.

\section{Discussion}

Our study used internationally standardised methods and provides the only English data for coronary event and case fatality rates that are directly comparable to those of the WHO MONICA project. The OXMIS included patients aged 65 years and more, the age group in which about two thirds of heart attacks occur, but which was excluded from the core MONICA project. The study also provides information about changes in coronary event and case fatality rates over the past three decades.

The age standardised event rates for men and women aged 35-64 years were low: they were only one third of those reported from the MONICA centres in Glasgow and Belfast, and were similar to rates in France and northern Italy. ${ }^{11}$ MONICA rates apply to the period 1985-87 whereas the current data were obtained in 1994-95, therefore the actual differences in rates within the UK may be less. Even allowing for some decline in rates in recent years, however, the difference is likely to be considerable. The substantially higher event rates for the age group 65-79 years compared to those less than 65 years underlines the importance of targeting interventions at older patients who are often excluded from preventive strategies.

The relatively low coronary event rate observed in Oxfordshire is likely to be real as under-ascertainment of cases is unlikely given the comprehensive, multiple overlapping, case finding methods used in the study. Non-fatal events classified as possible infarctions are most likely to be differentially included across studies and are a potentially important source of bias. ${ }^{16}$ If non-fatal possible infarcts are excluded from the comparison, however, large differences in event rates persist between the OXMIS and the UK MONICA centres. ${ }^{11}$ These geographical differences in coronary event rates may be explained partly by variation in conventional cardiovascular risk factors, especially smoking. ${ }^{17}$ Other risk factors may also be important-for example, dietary antioxidant intake, ${ }^{18}$ which is lowest in socioeconomic classes IV and $\mathrm{V}^{19}$ Lower socioeconomic status is not only associated with higher coronary incidence and mortality, but the Glasgow MONICA centre recently reported that it is also associated with decreased hospital admission. ${ }^{20}$ Socioeconomic difference may therefore account for some of the variation in rates between a relatively affluent population in Oxfordshire and the MONICA centres in Glasgow and Belfast, which include areas of economic deprivation. ${ }^{21}$

In contrast to coronary event rates, there were no marked differences between Oxfordshire and the UK MONICA centres in age standardised overall case fatality rates for patients aged less than $65 .{ }^{11}$ The 28 day case fatality rates for men in Oxfordshire, Glasgow, and Belfast were 39,49 , and $40 \%$, respectively. The corresponding rates for women were 36 , 49 , and $44 \%$. Other studies have also found that differences between populations in case fatality are much smaller than differences in incidence and mortality. ${ }^{22}$ As most deaths occur before reaching hospital, opportunities for reducing case fatality through improved hospital care are limited. Nevertheless, among patients admitted to hospital in Oxfordshire in 1994-95, the 28 day case fatality rates for men $(12 \%)$ and women (14\%) were lower than rates reported for several MONICA populations in the $1980 \mathrm{~s}^{22}{ }^{23}$ This may be explained by an improvement in prognosis because of increasing use of thrombolytic treatment, aspirin, $\beta$ blockers, and angiotensin converting enzyme inhibitors. It is consistent with our finding of higher rates of in-hospital administration of drugs for secondary prevention of myocardial infarction than previously reported in the $\mathrm{UK}^{24}$

We have demonstrated a substantial decline in coronary event and case fatality rates in Oxfordshire between 1966-67 and 1994-95. An important exception, however, was the $60 \%$ increase in non-fatal definite myocardial infarction events in women aged 50-69 years. This finding may be a result of chance or be related to the decline in smoking occurring some 10 years later in women who started smoking 20 years later than men. ${ }^{25}$ Unlike the Nottingham heart attack register, which showed no apparent change in inpatient mortality between 1982 and $1992^{4}$ despite advances in treatment, we found a reduction in one month case fatality in hospitalised men (43\%) and women (53\%) between 1966 and 1995 .

Care is needed in interpreting our results because different diagnostic criteria for myocardial infarction were used in the OXMIS and 1966-67 study. The original study used modified 1959 WHO criteria, ${ }^{7}$ while the OXMIS used WHO MONICA criteria. ${ }^{9}$ The major change is that current criteria use Minnesota ECG coding rather than more subjective ECG interpretation, and only $82 \%$ of cases categorised as definite infarction by the old criteria would fulfil the new criteria. ${ }^{26}$ The adoption of 
more stringent MONICA criteria could account for some of the decrease in coronary event rates. Increasing awareness among patients and clinicians of myocardial infarction as a possible diagnosis and more sensitive diagnostic tests, such as creatine kinase, ${ }^{27}$ however, may contribute to more complete case ascertainment offsetting some of the reduction in the proportion of patients diagnosed using the new ECG diagnostic criteria. Despite the difficulties of comparison, our findings suggest that coronary event rates have decreased by about one third in men, rather less in women, and that case fatality has fallen by nearly one third in men and women.

In summary, we have documented a decline in coronary event and case fatality rates in Oxfordshire. This suggests that a combination of reduced population risk factors, mainly as a result of decreased cigarette smoking and changes in diet, ${ }^{28}$ and improved medical care have contributed to reduced coronary mortality. A striking finding was that the event rate was only a third of that reported by the Glasgow and Belfast MONICA centres and similar to rates in France and northern Italy. Older patients aged 65-79 years were not studied in the MONICA project, and in these patients we found non-fatal and fatal myocardial infarction event rates to be two to fourfold higher than in younger patients. This emphasises the importance of including older patients in preventive strategies.

\footnotetext{
We thank the research nurses and administrative staff for help
with data collection and processing; general practitioners, with data collection and processing; general practitioners,
hospital staff, the coroner, and staff of the Oxfordshire hospital staff, the coroner, and staff of the Oxfordshire ambulance department, family health services authority, and district health authority for access to data; staff of the Glasgow KONICA centre for Minnesota coding; and Professor Leo Kinlen, Dr Pat Yudkin, Dr Caroline Mor
Hugh Tunstall-Pedoe for invaluable advice.

Hugh Tunstall-Pedoe for invaluable advice.
The work was funded by the NHS research and development

The work was funded by the NHS research and development
and Oxfordshire District Health Authority.

1 Tunstall-Pedoe H. Coronary heart disease. $B M \mathcal{F}$ 1991;303:701-4

2 Shaper AG. Geographic variations in cardiovascular mortality in Great Britain. Br Med Bull 1984;40:366-73. 3 Dargie HJ. Scottish hearts but British habits. $B M f$ 1989;299:1475-6.

4 Brown N, Young T, Gray D, et al. Inpatient deaths from acute myocardial infarction, 1982-92: analysis of data in the Nottingham heart attack register. BMf 1997;315:15964.

5 WHO MONICA Project Principal Investigators [prepared by Tunstall-Pedoe $\mathrm{H}$ ]. The World Health Organisation MONICA project (monitoring trends and determinants in cardiovascular disease): a major international collaboracardiovascular disease): a major interna
tion. f Clin Epidemiol 1988;41:105-14.
}

6 Kinlen LJ. A community study of acute myocardial infarction and sudden death. D Phil thesis. Oxford: University of Oxford, 1969

7 Kinlen LJ. Incidence and presentation of myocardial infarction in an English community. Br Heart f 1973;35:616-22.

8 Tunstall-Pedoe H. Problems with criteria and quality control in the registration of coronary events in the MONICA study. Acta Medica Scandinavica Supplementum MONICA study.

9 WHO MONICA project. MONICA manual. Geneva: Cardiovascular Diseases Unit, World Health Organisation, 1990.

10 Prineas RJ, Crow RS, Blackburn H. The Minnesota code manual of electrocardiographic findings. Standards and procedures for measurement and classification. Boston: John Wright PSG, 1982 .

11 Tunstall-Pedoe H, Kuulasmaa K, Amouyel P, et al. Myocardial infarction and coronary deaths in the World Health Organization MONICA project. Registration procedures, event rates, and case-fatality rates in 38 populations from 21 countries in four continents. Circulation 1994;90:583612.

12 Waterhouse J, Muir CS, Correa P, et al. Cancer incidence in five continents. Lyon: IARC, 1976.

13 Armitage P, Berry G. Statistical methods in medical research. Oxford: Blackwell Science, 1989.

14 Gardner MJ, Altman DG. Statistics with confidence. London: BMJ Publishing Group, 1994.

15 Kahn, HA, Sempos CT. Statistical methods in epidemiology. Oxford: Oxford University Press, 1989.

16 Beaglehole R, Dobson A, Hobbs M, et al. Comparison of event rates among three MONICA centres. Acta Medica Scandinavica Supplementum 1988;728:53-9.

17 Shaper AG, Pocock SJ, Walker M, et al. Risk factors for ischaemic heart disease: the prospective phase of the British regional heart study. $\mathcal{F}$ Epidemiol Community Health 1985;39:197-209.

18 Knekt P, Jarvinen R, Reunanen A, et al. Flavonoid intake and coronary mortality in Finland: a cohort study. BMf 1996;312:478-81

19 Gregory J, Foster $\mathrm{K}$, Tyler $\mathrm{H}$, et al. The dietary and nutritional survey of British adults. London: HMSO, 1990

20 Morrison C, Woodward M, Leslie W, et al. Effect of socioeconomic group on incidence of, management of, and survival after myocardial infarction and coronary death: analysis of community coronary event register. BMF 1997; 314:541-6.

21 McLoone P, Boddy FA. Deprivation and mortality in Scotland, 1981 and 1991. BMF 1994;309:1465-70.

22 Lowel H, Dobson A, Herman B, et al. Coronary heart disease case fatality in four countries. Circulation 1993:88: 2524-31.

23 Tunstall-Pedoe $\mathrm{H}$, Morrision C, Woodward M, et al. Sex differences in myocardial infarction and coronary deaths in the Scottish MONICA population of Glasgow 1985 to 1991. Circulation 1996;93:1981-92.

24 Dovey S, Hicks N, Lancaster T, et al. Secondary prevention after myocardial infarction: how completely are research findings adopted in practice? Eur $\mathcal{F}$ Gen Pract. [In press.]

25 Doll R, Darby S, Whitley E. Trends in mortality from smoking-related diseases. In: Charlton J, Murphy M, eds. The health of adult Britain 1841-1994. Volume 1. Series DS no. 12. London: Office for National Statistics, 1997:128-55.

26 Beaglehole R, Stewart AW, Butler M. Comparability of old and new World Health Organization criteria for definite myocardial infarction. Int $\mathcal{F}$ Epidemiol 1987;16:373-6.

27 Burke GL, Edlavitch SA, Crow RS. The effects of diagnostic criteria on trends in coronary heart disease morbidity: the Minnesota heart survey. $\mathcal{F}$ Clin Epidemiol 1989;42:1724.

28 Charlton J, Murphy M, Kay-tee K, et al. Cardiovascular diseases In: Charlton J, Murphy M. The health of adult Britain 1841-1994. Volume 2. Series DS no.12. London: Office for National Statistics: 1997:60-81. 